\title{
Bode, Barbara. Las campanas del silencio. Destrucción y creación en los Andes. Lima: Fondo Editorial del Congreso del Perú, 2015, 521 pp.
}

El libro publicado por el Fondo Editorial del Congreso es una traducción del original de 1989 No Bells To Toll. Destruction and creation in the Andes. Se trata de una etnografía del desastre que describe el profundo estado de shock que la población de Huaraz padeció tras la destrucción de su ciudad por el terremoto de mayo de 1970. Pero es también un relato sobre reconstrucción, anhelos de progreso y expectativas de una población que, tras haberlo perdido todo, choca con los aparatos del Estado revolucionario militar. El subtítulo del libro recoge los dos grandes temas explorados durante su estadía.

En la primera mitad, Bode se dedica dar contexto al Callejón de Huaylas y la ciudad destruida a partir de documentos historiográficos, así como de estudios geográficos y geológicos. La segunda mitad está abocada a analizar los discursos del ámbito nacional. Usando un estilo novelado y lleno de diálogos, la autora presenta la historia de diversos sobrevivientes, autoridades locales, burócratas del gobierno militar, párrocos y sacerdotes involucrados en la reconstrucción espiritual de Huaraz, entre otros. Los capítulos dedicados a narrar el «acontecimiento en sí mismo» son particularmente interesantes, pues en ellos discute la posibilidad de que el evento geológico exista por sí solo.

El terremoto resulta indesligable, para quienes lo sufrieron, de la historia previa y de los sucesos ocurridos luego de este. Hechos del pasado, como avalanchas y sucesos relacionados con las cruces y santos, parecían confundirse en la memoria de la gente. Así como las vidas de los sobrevivientes se entrelazaron profundamente como consecuencia de la experiencia compartida, los muertos del pasado se trasladaron a las narrativas del presente. Su destino empezó a ser interpretado mediante especulaciones y escenarios hipotéticos sobre qué habrían estado haciendo de no haber muerto antes. Para los huaracinos, las explicaciones científicas de los geólogos no resultaban suficientes para responder a la pregunta «¿por qué aquí?». Bode nos recuerda a Evans-Pritchard y su análisis de la hechicería entre los azande: «un campesino indígena está trabajando en su telar en un caserío en las faldas del Huascarán. Una roca lo aplasta. ¿Por qué esta coincidencia de la roca y el hombre? ¿Por qué este hombre y no otro que está barbechando su chacra?». La inquietud que atormentaba a los sobrevivientes más allá de explicaciones causales sobre la dinámica tectónica era la pregunta por la casualidad que permitió la tragedia de tantas familias. La respuesta, entonces, se abre a un abanico de posibilidades que involucran a los dioses y seres sobrenaturales que habitan el 
paisaje de los Andes, así como a la culpa y ansiedad sentida por los habitantes del Callejón respecto de sus prácticas rituales y devoción a las imágenes religiosas. En un contexto de ebullición política, las pugnas al interior de la Iglesia católica entre tradicionalistas y reformistas, así como el influjo de corrientes protestantes, apuntalaron el cuestionamiento de las costumbres religiosas de los campesinos y ciudadanos. El terremoto era un evidente castigo de Dios, pero ¿qué falta habían cometido? Acusaciones de falta de fe, pecado comunal e individual, cambios en la práctica de los sacramentos y de las fiestas, etc., fueron interpretados como posibles causantes de la ira del Dios cristiano, mezcladas con nociones andinas de reciprocidad con las montañas y los ancestros. La ambivalencia de la gente hacia el paisaje se agravó tras el terremoto: la belleza sublime de los nevados no se podía desligar de su carácter chúcaro y peligroso.

Las campanas del silencio es también un relato sobre la reestructuración de la sociedad desde una perspectiva política y religiosa. Como indica Bode, su propósito era estudiar los cambios en las creencias; sin embargo ahí donde ella «buscaba religión, encontraba revolución». El influjo de la Teología de la Liberación en las corrientes más progresistas de la Iglesia católica significó que muchos de los problemas de la sociedad huaracina fueran interpretados por los clérigos a través aparatos conceptuales mucho más terrenales que sus oponentes tradicionalistas y los mismos creyentes. Al mismo tiempo, encontró que los proyectos utópicos de los militares que tomaron el poder en 1968 estaban siendo tomados dogmáticamente, llevando a una curiosa situación en la que la sociedad era «sacralizada» y la religión «secularizada». El gobierno formuló un plan de Reconstrucción Revolucionaria para la ciudad de Huaraz que implicaba la destrucción del antiguo régimen de desigualdad y la renovación de las relaciones sociales basadas en la propiedad. Paralelamente a la reforma agraria que redistribuyó la tierra entre los campesinos que la trabajaban, se ejecutó una reforma urbana mediante la cual se esperaba construir una sociedad igualitaria. Bajo este paradigma se libró una lucha entre los planificadores estatales de CRYRZA (Comisión de Reconstrucción y Rehabilitación de la Zona Afectada) y los vecinos de Huaraz y Yungay. En la medida en que los reconstructores del régimen, aupados por un ímpetu modernizador, interpretaban la nostalgia y la conexión cultural con la tierra - el «terruño»— como indicadores de codicia, egoísmo y tradicionalismo, se agudizaba el conflicto entre los huaracinos y sus nuevos «directores» costeños.

Decisiones como la total expropiación de los terrenos de la ciudad, la moratoria a la compraventa de aquellos y la prohibición de reconstruir las viviendas 
a voluntad de los damnificados llevaron a que estos vivieran durante años en un entorno precario en campamentos sobrepoblados. CRYRZA empezó a ser visto como un obstáculo, o incluso como enemigo del pueblo de Huaraz. El rediseño de la ciudad bajo criterios modernos, con calles anchas y viviendas de concreto uniformes en forma y tamaño, se oponían al intenso deseo de volver a la normalidad de los afectados por el terremoto, de «volver al lugar de uno». Una «estética ajena» se imponía desde fuera, dejando de lado la historia de la ciudad y, más aún, ignorando su relación con el paisaje. Se temía que las nuevas viviendas parecieran más bien celdas sin vista a la Cordillera. Una batalla por la arquitectura parecía prefigurarse. A partir de entonces el plan estatal de reubicación en «unidades vecinales» apareció como una amenaza a la reconstrucción vernácula de los «barrios». La evaluación del riesgo de CRYRZA determinó, por otro lado, que el uso del adobe estaría a partir de entonces prohibido, privilegiando el concreto y ladrillo por sobre las técnicas constructivas tradicionales. Las palabras clave de los ingenieros de la costa eran «material noble» $\mathrm{y}$ «antisísmico».

La destrucción fue percibida por los huaracinos como un doble desastre: causado en primera instancia por el terremoto y luego por CRYRZA, cuya actividad fue concebida mediante un término acuñado tras la demolición deliberada de los restos de la ciudad: terremotear. La ciudad fue aplanada en su totalidad, con excepción de la cúpula de la antigua catedral, que fue dejada como símbolo del pasado. El poder del Estado aparecía como una muralla burocrática y dogmática que impedía a la gente reconstruir por sí misma su vida cotidiana.

Echando mano al concepto de communitas, Bode encuentra que el terremoto generó una desestructuración de las categorías que daban orden a la sociedad huaracina, rompiendo el tejido social y poniendo en juicio la forma en que la vida en comunidad se había estado llevando a cabo hasta entonces. La extensión de la catástrofe en todo el valle, y no solo en un poblado específico, llevó a que la gente se preguntara obsesivamente el porqué del sufrimiento conjunto: campesinos indios, mestizos urbanos y élites terratenientes lo perdieron todo por igual. ¿Es que la responsabilidad era compartida? El terremoto en sí mismo mostró a la gente el terrible poder de las fuerzas naturales subyacentes al paisaje, pero también «hizo vívidas las fuerzas sociales y culturales» que existían en el Callejón, llevando a la gente a cuestionarse por ellas. Las jerarquías y categorías étnicas inscritas en la geografía fueron removidas por el «drama tectónico». Este habría funcionado como un «nivelador cósmico» que repercutió en un desprendimiento de las cosas: los indios, de «no tener nada» en sus estancias de altura, obtuvieron cierta licencia para saquear los escombros de las ciudades; mientras los terrate- 
nientes que perdieron sus haciendas vieron con resignación complaciente cómo se apropiaban de lo que quedaba de sus ganados y riquezas.

El deseo de «volver al lugar de uno» y de retorno a la jerarquía previa se veía imposibilitado por CRYRZA y el hecho de que ahora «Huaraz era todo chacra». La ciudad aplanada y desnuda como un campo, así como el incremento del desplazamiento de campesinos de las alturas a las zonas bajas para acceder a los servicios de emergencia del Estado y de los organismos humanitarios, reforzaba esta imagen. El desastre abrió la ciudad a los campesinos, indianizándola. Este flujo siempre había existido, aunque regulado por los lazos de compadrazgo que permitían la circulación de bienes y personas entre el campo y la ciudad. La muerte significó el fin súbito de muchos de estos lazos. En consecuencia, para acceder a los bienes urbanos, los indios debieron instalarse permanentemente en los módulos de los campamentos, lado a lado con los mestizos. Asimismo, algunos mestizos que lo habían perdido todo en las ciudades debieron, a su vez, trasladarse a sus terrenos rurales, pues la moratoria solo era efectiva en el casco urbano.

Otro tema explorado por Bode es la relación entre lo local y lo global para explicar los acontecimientos de 1970. Si bien inicialmente nos da una imagen relativamente aislada y estereotípica de un «apartado pueblo en los Andes», la antropóloga poco a poco va tomando nota de lo conectada que se encontraba la sociedad del Callejón con los hechos del mundo y los principales actores internacionales. En la medida en que el porqué de la catástrofe era explicado en términos de pecado y castigo, las causas prácticas fueron entendidas como consecuencia de una provocación al universo por el progreso técnico y científico, expresado en el alunizaje de la NASA en 1969 y en los ensayos atómicos de Estados Unidos y Francia en Alaska y el atolón de Mururoa, respectivamente. La ciencia descontrolada del hombre le daba una sensación de poder que los campesinos del Callejón entendían como exagerada, si no grandilocuente, y que estaba ahora pasando factura a los habitantes de la tierra. Si bien muchos establecían una relación causal simple entre uno y otro fenómeno, el asunto era más complicado para otros. No solo el terremoto era consecuencia del atrevimiento de la ciencia, sino que la contaminación y la alteración del clima empezaban a ser interpretadas a partir de estos acontecimientos internacionales. Según Bode, el «drama tectónico» agudizó la conciencia meteorológica de los damnificados, produciendo una «sensación de transformación de su mundo». Los vientos eran percibidos como más fríos y las inundaciones más frecuentes.

El libro Las campanas del silencio reúne diversos temas, como modernización, religión y política, ecología, paisaje, tierra y propiedad, jerarquía, orden y 
revolución. Elementos siempre presentes en la cotidianidad que a partir del terremoto se «licuan» como la tierra que sostiene los campos y las ciudades, dejando expuesta la fibra subyacente a la vida en comunidad y poniendo en relieve las expectativas de cambio de la población.

Fabio Donayre Miranda

Pontificia Universidad Católica del Perú

\section{Resumen}

Reseña el argumento del libro destacando las maneras como las circunstancias políticas, eclesiales y culturales dieron forma a la interpretación que la población de Huaraz dio al desastre desatado por el terremoto de 1970 en el callejón de Huaylas.

Palabras clave: terremoto, desastre, gobierno militar, ayuda internacional, cultura andina, Iglesia católica. 